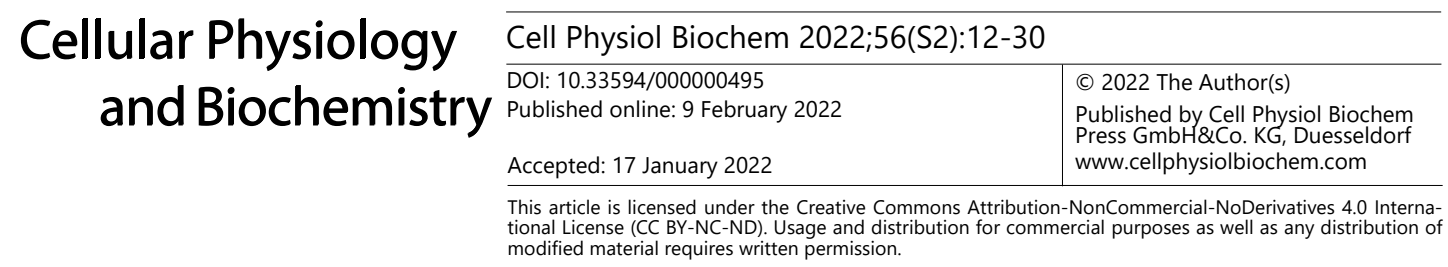

Review

\title{
Channels and Transporters in Astrocyte Volume Regulation in Health and Disease
}

\author{
Makenna M. Reed Bonnie Blazer-Yost \\ Indiana University Purdue University Indianapolis, Indianapolis, IN, USA
}

\section{Key Words}

Aquaporin 4 - Transient receptor potential vanilloid 4 - Sodium potassium chloride co-transporter - Volume regulated anion channel $\bullet$ Inwardly rectifying potassium channel • Regulated volume decrease

\begin{abstract}
Astrocytes are the second most abundant cell type in the central nervous system and serve various functions, many of which maintain homeostasis of the intracellular milieu in the face of constant change. In order to accomplish these important functions, astrocytes must regulate their cell volume. In astrocytes, cell volume regulation involves multiple channels and transporters, including AQP4, TRPV4, TRPM4, VRAC, Na ${ }^{+} / \mathrm{K}^{+}$ATPase, NKCC1 and Kir4.1. AQP4 is a bidirectional water channel directly involved in astrocyte cell volume regulation. AQP4 also forms heteromultimeric complexes with other channels and transporters involved in cell volume regulation. TRPV4, a mechanosensitive channel in involved in osmotic regulation in various cell types, forms a complex with AQP4 to decrease cell volume in response to cell swelling. TRPM4 also forms a complex with AQP4 and SUR1 in response to injury resulting in cell swelling. Another complex forms between $\mathrm{Na}^{+} / \mathrm{K}^{+}$ATPase, AQP4, and mGluR5 to regulate the perisynaptic space. NKCC1 is a co-transporter involved in cell volume increases either independently through cotransport of water or a functional interaction with AQPs. VRAC is implicated in regulatory volume decreases and may also functionally interact with AQP4. Although Kir4.1 colocalizes with AQP4, its role in cell volume regulation is debated. In diseases where fluid/electrolyte homeostasis is disturbed such as stroke, ischemic injury, inflammation, traumatic brain injury and hydrocephalus, cell volume regulation is challenged, sometimes past the point of recovery. Thus, a greater understanding of signaling pathways which regulate transport proteins as well as the functional and physical interactions that exist between transporters will provide a basis for the development of pharmaceutical targets to treat these prevalent and often devastating diseases.




\section{Cellular Physiology Cell Physiol Biochem 2022;56(S2):12-30 \\ and Biochemistry \begin{tabular}{l|l} 
Dublished online: 9 February 2022 & $\begin{array}{l}\text { P } 2022 \text { The Author(s). Published by } \\
\text { Cell Physiol Biochem Press GmbH\&Co. KG }\end{array}$
\end{tabular} \\ Reed et al.: Channels and Transporters in Astrocyte Volume Regulation}

\section{Introduction}

The extracellular fluids of the central nervous system (CNS) are comprised of blood, interstitial fluid (ISF) and cerebrospinal fluid (CSF). Collectively, these are responsible for functions such as hormone and cytokine signaling, CNS environment homeostasis, nutrient delivery, brain waste clearance, and brain cushioning. The composition of each of the fluids is distinct and the movement of water, small molecular weight components and even cells between compartments represent highly controlled processes [1-4]. There are several cell types that regulate the composition, movement, and clearance of the three different fluids. The choroid plexus secretes CSF into the brain's ventricular system where it is absorbed, dispersed, or drained by other cell types such as ependymal, meningeal, lymphatic, and glial cells [5]. The blood-brain barrier is one of the least permeable vascular systems in the body, although specific transport across this barrier does take place and disruption of the barrier is a common pathological occurrence in disease or injury [6-10]. On a more localized level, maintenance of the fluid composition, particularly in niches such as the perisynaptic domain and the perivascular space, is controlled by specialized cells called astrocytes [11].

Astrocytes are one of the most common CNS glial cells and are found throughout the brain. Astrocyte function depends on specific localization within the brain. Of importance are astrocytes found at the blood brain barrier (BBB), where they play a key role in maintenance of CSF and ISF [11]. Astrocytes form a layer adjacent to the pia mater called the glia limitans. The main function of these astrocytes is protection and regulation of CSF adjacent to pial vessels $[12,13]$. Alternatively, astrocytes with endfeet in close proximity to synaptic junctions, support neurons through maintenance of a constant extracellular milieu during neuronal activity, playing a supporting role in synaptic transmission and modulating information via the secretion of gliotransmitters [14-19]. Perivascular astrocytes are important in glymphatic function. The glymphatic system was first proposed as method of cerebrospinal fluid (CSF) and interstitial fluid (ISF) exchange and clearance [20]. CSF enters the periarterial space where it can be taken up by astrocytes and transported throughout the brain parenchyma to perivenous spaces and then drained through cervical lymphatics [20-24]. The glymphatic system has been proposed to be important in the clearance of brain waste and toxic materials, including amyloid $\beta[20]$.

In this review, we will focus on the transporters involved in the maintenance of the extracellular milieu and, as a consequence, cell volume in astrocytes under normal and pathological conditions (Table 1). Astrocytes are responsible for maintaining normal brain environment including electrolyte and fluid balance, which involves the uptake and removal of extracellular compounds. Notable in this regard is the removal of accumulating extracellular $\mathrm{K}^{+}$during times of high neuronal activity [25]. Glial cells in general, and astrocytes in particular, swell in response to a variety of injuries including ischemic injury, stroke, traumatic brain injury and inflammation [6-7]. Excitotoxicity, neuronal and vascular degeneration, and metabolic disruption can all be a result of detrimental glial swelling [26, 27]. Depending on severity, these processes can either be followed by a normal decrease in volume or abnormal function and cell death [28, 29].

Regulatory cell volume changes are mediated by transmembrane ion fluxes [30, 31]. Astrocytes contain key channels and transporters that are involved in either regulatory volume increase (RVI) or decrease (RVD) (Fig. 1). During RVD ions efflux from the cell, while during RVI, ions accumulate within the cell to maintain osmotic equilibrium. Simultaneous activation of these mechanisms is avoided through inhibition of the opposing mechanism [30, $32,33]$. The astrocytic channels and transporters that are currently implicated in cell volume regulation include the bidirectional water transporter, aquaporin-4 (AQP4), the osmo- and mechano-sensitive channel, transient receptor potential cation channel, subfamily vanilloid, member 4 (TRPV4), the sulfonylurea receptor 1 (SUR1)-transient receptor potential melastatin 4 (TRPM4) complex, the volume-regulated anion channel (VRAC), the inwardly rectifying potassium channel (Kir4.1), sodium potassium adenosine triphosphatase pump $\left(\mathrm{Na}^{+} / \mathrm{K}^{+}\right.$ATPase) and $\mathrm{Na}^{+}-\mathrm{K}^{+}-\mathrm{Cl}^{-}$cotransporter (NKCC1) (Fig. 2). 


\section{Cellular Physiology and Biochemistry}

Cell Physiol Biochem 2022;56(S2):12-30

\begin{tabular}{l|l}
\hline DOI: 10.33594/000000495 & (c) 2022 The Author(s). Published by \\
\hline
\end{tabular}

Reed et al.: Channels and Transporters in Astrocyte Volume Regulation

Table 1. Experimental Manipulation of Astrocyte Channels and Transporters, their effects, and associated pathology. 2-(nicotinamide)-1,3,4-thiadiazole, TGN-020; RVD, regulatory volume decrease; TBI, traumatic brain injury; SCI, spinal cord injury; $4 \alpha$ PDD, $4 \alpha$-phorbol 12,13-didecanoate; MCAO, middle cerebral artery occlusion; ICH, intracerebral hemorrhage; BBB, blood brain barrier

\begin{tabular}{|c|c|c|c|}
\hline Channel/Transporter & Experimental Manipulation & Effects/Results & Pathology \\
\hline \multirow[b]{2}{*}{ AQP4 } & Global mouse knockout [51] & $\begin{array}{l}\text { Decreased water permeability [34], Problems } \\
\text { with cell migration [52], K+ buffering [53], } \\
\text { cognition [54-58], impaired cell adhesion [59] }\end{array}$ & $\begin{array}{l}\text { Beneficial for Cytotoxic Edema [68,69], } \\
\text { not Vasogenic Edema [71], Ischemia [68] }\end{array}$ \\
\hline & Hypoosmotic Stress & $\begin{array}{l}\text { Locates to Plasma Membrane }[72,73] \text {, } \\
\text { RVD triggered }[35,66,67]\end{array}$ & $\begin{array}{l}\text { Postulated role in Alzheimer's Disease [63], } \\
\text { Hydrocephalus [64, 65], TBI [8], SCI [74], } \\
\text { Vasogenic Edema [70] }\end{array}$ \\
\hline \multirow{5}{*}{ TRPV4 } & $\begin{array}{l}\text { Global mouse knockout, } \\
\text { osmotic stress [85] }\end{array}$ & $\begin{array}{l}\text { Problems with systemic tonicity } \\
\text { homeostasis [85] }\end{array}$ & $\begin{array}{l}\text { Improved outcome with induced Ischemic } \\
\text { injury [91] }\end{array}$ \\
\hline & TRPV4 siRNA knockdown [9] & Reduced hypotonicity $\left[\mathrm{Ca}^{2+}\right]$ influx [35] & $\begin{array}{l}\text { ICH, Edema, Ameliorated neurological } \\
\text { symptoms, neural death, BBB disruption } \\
\text { [10] }\end{array}$ \\
\hline & $\begin{array}{l}\text { Agonist: } \\
\text { GSK1016790A [9, 92, 93, 95] } \\
4 \alpha \text { PDD }[35,95]\end{array}$ & $\begin{array}{l}\text { Stress fiber formation, adherens and tight } \\
\text { junction degradation [9], dose dependent } \\
\text { neuronal death [92], Glial activation [93], } \\
\text { increased neuronal activity [95], No effect on } \\
\text { astrocyte calcium dynamics [35] Angiogenesis, } \\
\text { Neurogenesis [96] }\end{array}$ & $\begin{array}{l}\text { ICH, Edema, ameliorated neurological } \\
\text { symptoms, neural death, BBB disruption [9], } \\
\text { ICH, improved neurological and motor } \\
\text { outcomes [95], MCAO [92, 96], stroke, } \\
\text { Reduced infarct volume, improved functional } \\
\text { outcomes [96] }\end{array}$ \\
\hline & $\begin{array}{l}\text { Antagonist: } \\
\text { HC-067047 }[9,92,93] \\
\text { RN1734 }[97,98]\end{array}$ & $\begin{array}{l}\text { No effect on swelling [93], Reduced microglial } \\
\text { activation, reduced expression of TRPV4 [97] }\end{array}$ & $\begin{array}{l}\text { ICH, Edema, Ameliorated neurological } \\
\text { symptoms, neural death, BBB disruption [9], } \\
\text { MCAO [92], Demyelination [97], } \\
\text { Hydrocephalus [98] }\end{array}$ \\
\hline & $\begin{array}{l}\text { Gadolinium/Ruthenium Red } \\
\text { (Inhibition) }\end{array}$ & No effect on RVD kinetics [47] & \\
\hline \multirow{2}{*}{ NKCC1 } & Bumetanide $[115,10]$ & Decreased AQP4 and NKCC1 expression [115] & TBI [115], SCI [10] \\
\hline & TGN-20 (AQP4 inhibitor) [10] & Decreased edema [10] & \\
\hline \multirow[b]{2}{*}{ VRAC } & $\begin{array}{l}\text { Hypotonic challenge/Swelling } \\
\text { [117-125] }\end{array}$ & $\begin{array}{l}\mathrm{Cl} \text { and organic osmolyte efflux [119-122], } \\
\operatorname{RVD}[119,123-125]\end{array}$ & \\
\hline & $\begin{array}{l}\text { siRNA knockdown } \\
{[118,119,121,122]}\end{array}$ & $\begin{array}{l}\text { Suppressed hypotonic-stimulated amino acid } \\
\text { release [118], Reduced cell volume } \\
\text { recovery/RVD }[119,121,122]\end{array}$ & Epileptic seizures [120] \\
\hline \multirow{2}{*}{ Kir4.1 } & Extracellular $\mathrm{K}^{+}[25,127]$ & Localized swelling $[25,127]$ & \\
\hline & $\mathrm{BaCl}_{2}$ (blockage) [25] & No effect on extracellular space volume [25] & \\
\hline
\end{tabular}


Fig. 1. Channels and Transporters Involved in Compensatory Volume Changes. Astrocytes utilize channels and transporters localized to endfeet to regulate their external and internal osmotic environment. AQP4, TRPM4, $\mathrm{Na}^{+} / \mathrm{K}^{+}$ATPase, NKCC1, and Kir4.1 are proposed to be involved in influx of water leading to astrocytes swelling, called regulatory volume increase. During cell swelling, a complex formed between TRPM4 and AQP4 transitions the water channel from astrocyte endfeet to the cell body membrane. AQP4, TRPV4, and VRAC are involved in efflux of water from astrocytes, called regulatory volume decrease (RVD). Figure created with BioRender software (BioRender.com).

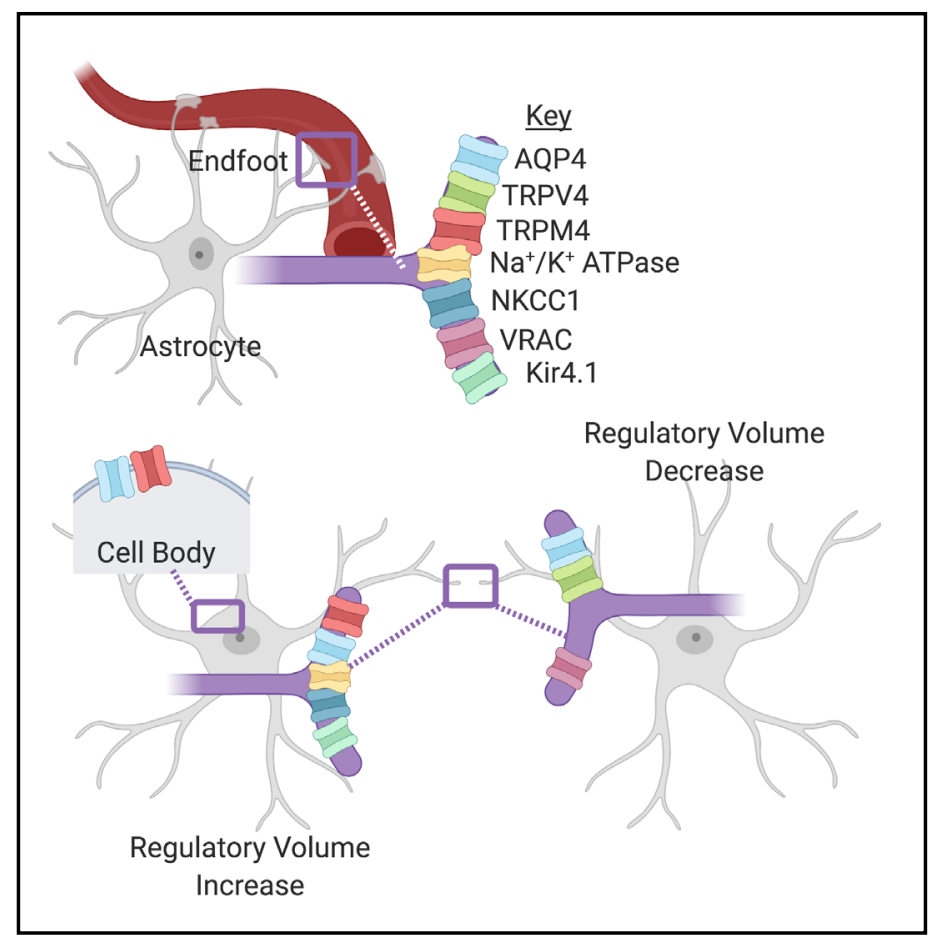

Fig. 2. AQP4 forms various heteromultimeric complexes with other channels and transporters. When astrocytes are presented with osmotic challenges, they utilize two processes: regulatory volume increase (compensatory swelling) and regulatory volume decrease (RVD). As a result, AQP4 can form several heteromultimeric complexes to contribute to these processes. In response to swelling and resulting membrane stretch, TRPV4 influxes calcium into the cell. As a result, it activates AQP4 to expel water from the cell, a process called RVD. Injury causes AQP4

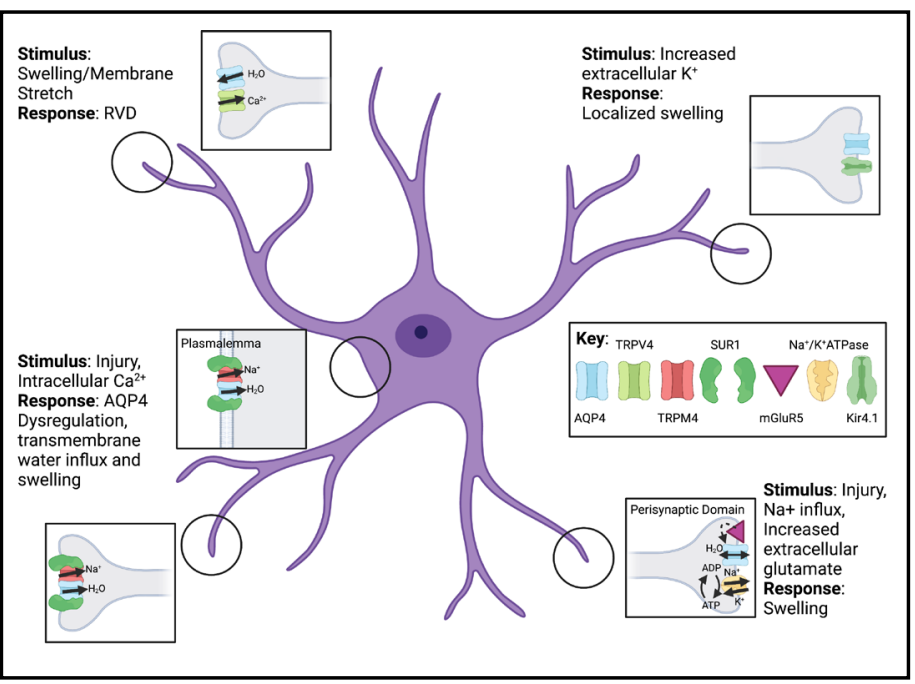
to switches binding partners from TRPV4 to TRPM4 complexed with SUR1. As a result, AQP4 become dysregulated and can now also be found in the plasmalemma of the cell body. This overall results in water influx and cell swelling. In the perisynaptic domain, $\mathrm{Na}^{+} / \mathrm{K}^{+}$ATPase, AQP4, and mGluR5 interact to regulate the extracellular space in response to injury resulting in swelling. AQP4 is also known to interact with Kir4.1, however, its role in cell volume regulation is not well understood. All of these complexes are important in astrocyte responses to osmotic challenges and cell volume regulation. Figure created with BioRender software (BioRender.com). 


\section{Cellular Physiology Cell Physiol Biochem 2022;56(S2):12-30 \\ \begin{tabular}{ll|l} 
and Biochemistry & $\begin{array}{l}\text { DOI: 10.33594/000000495 } \\
\text { Published online: } 9 \text { February } 2022\end{array}$ & $\begin{array}{l}\text { C } 2022 \text { The Author(s). Published by } \\
\text { Cell Physiol Biochem Press GmbH\&Co. KG }\end{array}$ \\
\hline
\end{tabular} \\ Reed et al.: Channels and Transporters in Astrocyte Volume Regulation}

\section{AQP4}

Aquaporins (AQPs) are a family of water transporting proteins with tissue-specific expression. In the brain, simple diffusion of water also occurs, though in a limited capacity in comparison to water transport by aquaporins $[34,35]$. The most abundant water channel in the brain is AQP4, found in astrocytes, and the ependyma, which is a layer of epithelial cells lining the cerebrospinal fluid-containing ventricular system [36, 37]. AQP4 is most commonly found at brain-fluid interfaces, including the endfeet of astrocytes [38-40].

Several isoforms of AQP4 have been identified, termed AQP4a-f [41]. AQP4a, AQP4c, and $\mathrm{AQP} 4 \mathrm{e}$, the most common plasma membrane isoforms play an active role in volume regulation [42-47]. AQP4e is a vesicle associated isoform that may regulate the plasma membrane localization of other AQP4 isoforms under conditions of hypoosmotic stress $[48,49]$. AQP4b and AQP4d isoforms are located in the cytoplasm and within endosomes and lysosomes of the endoplasmic reticulum. It was previously thought that these isoforms did not have a role in volume regulation. However, when isolated rat cortical astrocytes are exposed to hypoosmotic conditions, both isoforms relocated to early endosomes and may be important for other AQP4 isoform assembly and redistribution to the plasma membrane [50]. Theoretically the ability to target these different isoforms may be a beneficial therapeutic strategy for disorders arising from osmotic dysregulation.

In astrocytes, $\mathrm{AQP} 4$ is important for processes related to its function as an osmoregulatory transport protein. In a whole body AQP4 knockout mouse [51], several observations were made including, decreased astrocyte water permeability and cell migration [34, 52], decreases in $\mathrm{K}^{+}$buffering [53], changes in normal cognitive function through reduced basal neurotransmitters and downregulation of glutamate transporters [54-58], decreased channel-mediated astrocyte cell adhesion [59], and changes in brain extracellular space regulation [60,61]. Early in development, AQP4 can also be seen in radial glial cells (RGC), which have roles in neural organization and late glial differentiation [62].

AQP4 has also been reported to have a role in neurological diseases. AQP4 on astrocyte endfeet helps fluid and waste products move from periarterial spaces through the rest of the brain to be cleared in the perivenous spaces and, ultimately, through the glymphatic system [20]. In the APP/PS1 mouse model of Alzheimer's disease, deletion of AQP4 increased amyloid $\beta$ pathology $[46,63]$. In induced animal models and human patients with hydrocephalus, AQP4 was found to be increased specifically at blood brain barriers $[47,48,64$, 65]. This implicates a role for AQP4 in disease presentation, pathological progression, or an attempt to recover homeostasis.

The role of AQP4 in astrocyte volume regulation is key to normal and pathological processes. AQP4 expressed on the cell membrane is bidirectional and, therefore functional in cell swelling as well as a passive return to normal volume or an active, more rapid process of RVD mediated by both water and ionic flux. Transient swelling of astrocytes is a normal occurrence during astrocyte function of absorbing osmolytes, particularly $\mathrm{K}^{+}$, from the extracellular milieu after neuronal activity. Under abnormal conditions, swelling in the CNS, predominately in astrocytes, occurs acutely after traumatic brain injury, hemorrhage, hypoxia or inflammatory responses.

Cell swelling triggers RVD, a complex process involving the efflux of both water and solutes. Jo et al. found that cell swelling in response to hypotonic challenge induced an intracellular $\mathrm{Ca}^{2+}$ signal that, in turn, initiated RVD in dissociated mouse retinal glial cells [66]. AQP4 was shown to be involved in RVD of mouse primary brain astrocytes [35]. Interestingly, both of these studies found the AQP4-mediated RVD involved an interaction with TRPV4 as elucidated in more detail below.

Swelling or shrinking of astrocytes may vary according to the precipitating cause of intracellular and extracellular changes. This was elegantly demonstrated by Risher et al., who performed in vivo imaging of both astrocytes and pyramidal neurons using two photon laser scanning microscopy through cranial windows and then conducted confirmatory studies in mouse cortical brain slices [67]. They found that, as expected, astrocytes swell 


\section{Cellular Physiology Cell Physiol Biochem 2022;56(S2):12-30 \\ \begin{tabular}{ll|l} 
and Biochemistry $10.33594 / 000000495$ & P 2022 The Author(s). Published by \\
Published online: 9 February 2022 & Cell Physiol Biochem Press GmbH\&Co. KG
\end{tabular} \\ Reed et al.: Channels and Transporters in Astrocyte Volume Regulation}

during hypoosmotic challenge, extracellular $\mathrm{K}^{+}$elevations or oxygen/glucose deprivation. In the case of osmotic challenge, the pyramidal neurons did not swell, a finding which the authors attributed to the lack of AQPs in these neurons. The reversal of astrocyte swelling when the osmotic concentration returned to normal was relatively long, consistent with passive water flux rather than an active RVD. On the other hand, both neurons and astrocytes swelled in response to global ischemia during in vivo studies, and oxygen/glucose deprivation mimicking that pathological situation in brain slices. The neurons did not recover normal volumes on return to re-oxygenation/normoglucose conditions while the astrocytes showed a rapid recovery of cell volume consistent with RVD although the authors did not specifically demonstrate the RVD [67]. Thus, the processes of both swelling and return to normal cell volume may be dependent on the original stimulus and, by analogy, different regulatory controls.

To mitigate the development of cytotoxic edema or the accumulation of water inside cells, deletion of AQP4 was found to be beneficial [68-70] while AQP4 deletion exacerbated vasogenic edema or fluid accumulation in extracellular spaces in mice [71]. Genetic deletion of AQP4 in mice reduced the brain edema after water intoxication or ischemic stroke, two processes that acutely cause cell swelling [68]. Conversely, AQP4 facilitates reabsorption of excess fluid in vasogenic edema [70-71]. Thus, it is problematic to propose direct regulation of AQP4 for the treatment of hemorrhage, stroke or ischemic injury, since over time cytotoxic edema often progresses to vasogenic edema.

Regulation of AQP4 in both cell swelling and RVD takes place via different mechanisms and in some cases, in a cell-specific manner. Neri et al. found increases in AQP4 expression in cases of edema following traumatic brain injury (TBI) in humans [8]. In rat and human cultured astrocytes, AQP4 abundance on the cell surface was found to be regulated by changes in tonicity [72, 73]. In a recent paper, Kitchen et al. showed that AQP4 was inserted into the plasma membrane in response to hypoxia in rat and human cultured astrocytes and HEK293 cells and also in a rodent model of spinal cord injury (SCI) [74]. The mechanism of the AQP4 translocation involved protein kinase A, cAMP, $\mathrm{Ca}^{2+}$ and calmodulin. Pharmacologically targeting the calmodulin inhibited the translocation of AQP4 to the membrane and decreased injury-induced edema [74].

Several drugs have been used to target AQP4 including acetazolamide and antiepileptic drugs, however, these are not specific for the water channel $[70,75,76]$ and have not been demonstrated to be clinically useful for the treatment of brain swelling. A specific AQP4 inhibitor called 2-(nicotinamide)-1,3,4-thiadiazole (TGN-020) was shown to have beneficial effects in ischemic cerebral edema and SCI in rodents [77-79]. As noted in the previous paragraph, targeting calmodulin is an essential component of AQP4 translocation to the membrane. Trifluoperazine, an FDA approved calmodulin antagonist for the treatment of psychosis, had beneficial effects on SCI edema and enhanced functional recovery in rats [74]. Regulators of AQP4 may be more beneficial pharmacological targets than the water channel itself.

AQP4 interacts with several other proteins and channels important to astrocyte volume regulation, such as TRPV4, TRPM4, and $\mathrm{Na}^{+} / \mathrm{K}^{+}$ATPase and Kir4.1 [36, 80, 81]. These channels and their interaction with AQP4 will be elaborated on in subsequent sections.

\section{TRPV4}

TRPV4 is a mechano-, osmo-sensitive ion channel [82], shown to participate in osmotic regulation in many cell types $[66,67,83,84]$. TRPV4 knock out mice grow and reproduce normally but when osmotically stressed, experience problems with osmotic equilibrium [85]. On the other hand, these mice showed reduced lesion volume and Evans blue leakage after induced ischemic injury [85]. As evidenced by these studies, TRPV4 is important in CNS fluid homeostasis. Along with other channels important in astrocyte osmoregulation, TPRV4 is expressed in astrocyte endfeet $[86,87]$. 
Benfenati et al. found that in both in vivo and in vitro rat astrocytes, TRPV4 formed a complex with membrane localized AQP4. They proposed that TRPV4 and AQP4 physically interact and participate in RVD [36]. These conclusions were based on the observation that depletion of AQP4 abolishes the $\mathrm{Ca}^{2+}$ increase normally seen in response to hypotonic stress. Since AQP4 is not $\mathrm{Ca}^{2+}$ permeable, the interaction with the osmosensitive TRPV4 $\mathrm{Ca}^{2+}$ channel was postulated to serve as the activator for astrocyte RVD. The authors showed a physical interaction between the two transporters that was required for subsequent downstream signaling [36].

RVD was also shown to involve both AQP4 and TRPV4 in Müller astroglia in the mouse retina [67]. TRPV4 was necessary for both hypotonic swelling and RVD. However, in the Müller cells, the two proteins were not observed to physically interact but, rather, water flux through AQP4 activated a swelling sensor that stimulates TRPV4-mediated $\mathrm{Ca}^{2+}$ entry which, in turn, modulates volume regulation, swelling and, interestingly, Aqp4 and Kir4.1 gene expression [67].

In mouse primary astrocyte cultures and in an established type 1 astrocyte primary culture cell line, DI TNC1, Mola et al. found that inhibition of TRPV4 with either gadolinium or ruthenium red decreased $\mathrm{Ca}^{2+}$ influx but had no effects on RVD kinetics measured with total internal reflection and quenching fluorescent assays [48]. These experiments remain to be repeated with more specific TRPV4 antagonists. The authors proposed instead that RVD is triggered by membrane stretch as a result of water influx from AQPs [48].

These seemingly discrepant findings may be explained by the diversity of astrocyte cell characteristics in different parts of the brain. Benfenati and colleagues made the interesting observation that the AQP4/TRPV4 complex is most abundant in what they termed superficial astrocytes - those that are found in the subarachnoid and perivascular spaces where they are likely to play a role in the export of osmolytes to the CSF in response to acute hypoosmotic stress. On the other hand, those astrocytes which have endfeet surrounding the smaller vessels of the vasculature in the brain parenchyma express predominately AQP4 alone which may play a role in water influx into the astrocytes [36]. The distinction of whether the AQP4 is complexed with TRPV4, effective independently, or works in combination with other channels has implications for differences in overall function in various parts of the brain. It also provides an explanation for why, in some experimental paradigms, the astrocytic TRPV4 appears to play a role in cell swelling and in other cases in RVD.

As an understanding of roles of TRPV4 in the brain evolves, knowledge regarding potential effectors of this channel are also evolving. There are several specific agonists and antagonists of TRPV4 [88], including orally bioavailable forms [89]. These experimental drugs, which have been used in preclinical animal models, have been extended by the recent elucidation of clinically useful TRPV4 antagonists (Clinical trials.gov, search term TRPV4) [90]. Negligible phenotypes in TRPV4 knockout mice under normal physiological conditions suggest that TRPV4 can be inhibited without significant side effects [91]. However, caution must be exercised in pathological situations given the lack of understanding of the roles of TRPV4 in the rest of the body.

Studies in animal models of intracerebral hemorrhage (ICH) have also produced conflicting results. Using autologous blood injection, Zhao et al. have demonstrated that a TRPV4 antagonist reduced brain edema and ameliorated neurological symptoms, neural death and blood-brain barrier disruption in a rat model of ICH [9]. Shen et al. found that ICH leads to TRPV4 overexpression resulting in a loss of $\mathrm{Ca}^{2+}$ homeostasis, inducing an ER unfolded protein response and neural apoptosis which was accompanied by cerebral edema [92]. Specific TRPV4 activation also induced dose dependent apoptosis and neuronal death, and glial activation in cell cultures and a middle cerebral artery occlusion (MCAO) [93, 94]. Together, these findings suggest that antagonism of TRPV4 may have beneficial effects. In contrast, other studies have indicated that increasing activity with TRPV4 agonists have a beneficial effect on ICH. A specific TRPV4 agonist improved selected neurological and motor outcomes in cerebral hemorrhage. Interestingly these effects occurred in the absence of other beneficial changes such as injury-induced increases in brain volume, edema or GFAP- 
positive astrocytes [95]. Likewise, TRPV4 activation with $4 \alpha$-phorbol 12,13-didecanoate reduced infarct volume and improved functional outcomes in a (MCAO) model of stroke. There was a 3.4-fold increase in microvessel density and an increase in neurogenesis [96]. It should be noted that the agonist used is not effective in the activation of TRPV4 in all tissues and, as all phorbol esters, may have other effects including mitogenic activity. The mitogenic activity of $4 \alpha$ PDD may explain the differences seen between the two distinct TRPV4 agonists in the MCAO models. The utilization of specific agonists will be important in future studies examining TRPV4.

In preclinical studies, antagonizing TRPV4 has shown benefits in reducing microglial activation in a cuprizone-induced mouse model of demyelination [97] and in the treatment of congenital hydrocephalus [98]. In the former case the mechanism of action was proposed to be an increase in TRPV4 expression coupled with a TRPV4-mediated increase in inflammatory mediators; in the latter case a TRPV4-mediated decrease in CSF accumulation was postulated.

Thus, there are conflicting findings whether inhibition or activation of TRPV4 is more beneficial in a number of brain pathologies that involve fluid homeostasis and volume regulation. This may be due to the experimental parameters monitored in each study. For example, activation of TRPV4 may be beneficial in neuronal and endothelial cells [95, 96], while TRPV4 antagonism may be beneficial in other cell types $[9,93,94,97,98]$. The role that TRPV4 plays in each cell type may also differ, for example proliferation in neurons and endothelial cells and inflammation in microglia and astrocytes. The differences could also be due to the nature of the disease and the degree of severity. Utilizing several different animal and cell culture models with the same experimental parameters and identical agonists or antagonists may be able to resolve some of the conflicting findings in these studies. This underscores the necessity of a more complete understanding of the nature of the diseases and the exact cell types affected before treatment options are developed.

\section{TRPM4}

Transient receptor potential melastatin 4 (TRPM4) is a monovalent cation permeable channel that has been shown to be substantially upregulated after CNS injury such as hypoxia-ischemia, TBI, and stroke in rodents and humans [99-102]. When expressed, the TRPM4 forms a complex with the sulfonylurea receptor 1 (SUR1) and this complex has been implicated in astrocyte volume increases and brain edema [99-102]. Recently Stokum et al. elucidated a mechanism involving the formation of a heteromultimeric complex of TRPM4SUR1-AQP4 as the causative ion and water transporter complex involved in astrocyte swelling [80]. In a series of elegant in vitro and in vivo studies, the authors found that when TRPM4 was expressed, AQP4 switches from an association with TRPV4 to TRPM4. This was found to be concurrent with the movement of the AQP4 from the astrocyte endfeet to the plasma membrane of the cell body. The experiments demonstrating the role of the complex in astrocyte swelling were first performed in COS-7 cells over-expressing various combinations of the multimeric components. The outcome of the COS- 7 results was reproduced in primary astrocyte cultures activated by a cytokine cocktail that causes TRPM4 expression. The in vitro finding that the multimeric complex caused astrocyte swelling was substantiated in vivo in a cold injury model of edema. In addition, genetic ablation of TRPM4 inhibited the coldinduced astrocyte swelling [80]. Thus, the TRPV4-AQP4 complex appears to be important for cell volume regulation under normal homeostatic conditions [36], while a TRPM4-SUR1$\mathrm{AQP} 4$ complex is functional during injury-induced astrocyte swelling.

As pointed out by Stokum and colleagues, the complex formation provides a means to indirectly inhibit AQP4 on astrocyte endfeet under pathological conditions [80]. This heteromultimeric complex may explain the efficacy of glibenclamide (a sulfonylurea) after ischemic stroke [101-103]. Several options are being developed to target TRPM4 including specific chemical inhibitors [104], and TRPM4 blocking antibodies [105] however these approaches are still being investigated clinically. 


\section{Cellular Physiology Cell Physiol Biochem 2022;56(S2):12-30 \\ \begin{tabular}{ll|l} 
and Biochemistry & $\begin{array}{l}\text { DOI: 10.33594/000000495 } \\
\text { Published online: } 9 \text { February } 2022\end{array}$ & $\begin{array}{l}\text { C } 2022 \text { The Author(s). Published by } \\
\text { Cell Physiol Biochem Press GmbH\&Co. KG }\end{array}$ \\
\hline
\end{tabular} \\ Reed et al.: Channels and Transporters in Astrocyte Volume Regulation}

\section{$\mathrm{Na}^{+} / \mathrm{K}^{+}$ATPase}

$\mathrm{Na}^{+} / \mathrm{K}^{+}$ATPase is an energy-dependent antiporter of sodium and potassium responsible for maintaining the electrolyte gradients across plasma cell membranes. The activity of the pump is dependent on the availability of ATP but is also sensitive to the concentrations of each of its ligands. Thus, both intracellular $\mathrm{Na}^{+}$as well as extracellular $\mathrm{K}^{+}$can alter pump dynamics. Recent studies have implicated this transporter as a major factor in astrocyte swelling induced by high extracellular $\mathrm{K}^{+}$concentrations $[25,106]$.

The transporter is composed of a tetramer of $\alpha$ and $\beta$ subunits with several known isoforms of each subunit. Studies of the isoform-specific characteristics when expressed in Xenopus laevis oocytes showed differing affinities for both $\mathrm{Na}^{+}$and $\mathrm{K}^{+}$. The glial form of the $\mathrm{Na}^{+} / \mathrm{K}^{+}$ATPase is $\alpha 1 / \beta 1$ which is notable because this complex shows maximal transport activity under conditions of raised extracellular $\mathrm{K}^{+}[25]$. These authors found that $\mathrm{Na}^{+} / \mathrm{K}^{+}$ ATPase is a key component of the astrocyte-mediated $\mathrm{K}^{+}$clearance pathway in freshly isolated rat hippocampal slices. The findings were substantiated and extended by Walch and colleagues who showed that in freshly prepared mouse brain slices, changes in extracellular $\mathrm{K}^{+}$within the physiological range caused astrocyte, but not neuronal, swelling [106]. The authors suggest that this is due to the difference in $\mathrm{Na}^{+} / \mathrm{K}^{+}$ATPase subunit expression. Neurons express the $\alpha 1 / \beta 1$ subunit which is differentially sensitive to increases in intracellular $\mathrm{Na}^{+}$. Additionally, the astrocyte-selective volume increase in response to elevated extracellular $\mathrm{K}^{+}$was independent of AQP4 [106]. However, interpretation of some aspects of the studies listed above are complicated by the use of oubain and the resulting inability of the cells to establish normal $\mathrm{Na}^{+}$and $\mathrm{K}^{+}$transmembrane gradients.

In contrast to the finding summarized above, Illarionova et al. found that $\mathrm{Na}^{+} / \mathrm{K}^{+}$ ATPase and AQP4 co-localize and functionally interact in rat astrocytes [81]. These authors demonstrated a complex consisting of a transporting microdomain of AQP4, $\mathrm{Na}^{+} / \mathrm{K}^{+}$ATPase and the metabotropic glutamate receptor 5 (mGluR5) using both pull-down assays and FRET localization. They also elucidated the amino acid residues in the N-terminus of AQP4 that bind to the pump. During increased neuronal activity, as in the case of injury, glutamate is released by neurons and taken up by astrocytes. This uptake of glutamate also results increased uptake of $\mathrm{Na}^{+}$by glutamate- $\mathrm{Na}^{+}$cotransporters. As a response, mGluR5 activates $\mathrm{AQP} 4$, resulting in water influx. This is thought to help buffer intracellular $\mathrm{Na}^{+}$concentration in the vincinity of the $\mathrm{Na}^{+} / \mathrm{K}^{+}$ATPase. This heteromultimeric complex seems to be important in neuron-astrocyte crosstalk and, as a result, changes in astrocyte cell volume.

Characterizing the role of the $\mathrm{Na}^{+} / \mathrm{K}^{+}$ATPase pump and its interacting proteins is important for understanding astrocyte swelling in normal and pathological states. The pump is, however, not a good drug target since diminishing its activity can be detrimental to normal cell activity and disturbs ion gradients [107].

\section{NKCC1}

NKCCs are electroneutral co-transporters which allows the cellular influx of sodium, potassium and chloride in a 1:1:2 ratio. These transporters are involved in fluid/volume homeostasis in many systems and inhibition of NKCC has been shown to be beneficial in cases of fluid dysregulation such as cerebral ischemia and vasogenic brain edema $[108,109]$. NKCC2 is found predominately in renal cells while NKCC1 is widely distributed. In the brain, NKCC1 is found in astrocytes as well as neurons, oligodendrocytes, choroid plexus epithelia and blood vessel endothelial cells. This triple co-transporter has unique roles in each of the brain cell types [108].

In astrocytes, NKCC1 is activated by high extracellular $\mathrm{K}^{+}$, a hallmark of neuronal activity as well as by brain ischemia. While this may be an important homeostatic role in normal conditions, it results in astrocyte swelling in pathological conditions [25, 107, 110113]. In AQP4 rodent knockouts, water still enters astrocytes [35-36]. One explanation for 


\section{Cellular Physiology Cell Physiol Biochem 2022;56(S2):12-30 \\ \begin{tabular}{ll|l} 
and Biochemistry & $\begin{array}{l}\text { DOl: 10.33594/000000495 } \\
\text { Published online: } 9 \text { February } 2022\end{array}$ & $\begin{array}{l}\text { O } 2022 \text { The Author(s). Published by } \\
\text { Cell Physiol Biochem Press GmbH\&Co. KG }\end{array}$ \\
\cline { 2 - 3 } &
\end{tabular} \\ Reed et al.: Channels and Transporters in Astrocyte Volume Regulation}

this phenomenon is the expression of water co-transporters, such as NKCC1. In oocytes, exogenous expression of NKCC1 was used to determine water influx through the transporter. The authors reported that NKCC1 acted as a water pump and reported a net gain of 460 water molecules for each $\mathrm{Na}^{+} \mathrm{K}^{+} 2 \mathrm{Cl}^{-}$[114]. While these findings are not universally accepted, there are many studies indicating that co-transporters of this class can transport water molecules and may contribute to the overall water influx into cells.

Studies have implicated interactions between NKCC1 and AQP4 in astrocyte cell volume regulation, particularly under pathological conditions. In a mouse model of traumatic brain injury, Zhang and colleagues found that both AQP4 and NKCC1 were up-regulated in the cerebral cortical astrocytes of the peri-contusional brain tissue [115]. These authors used astaxanthin, an antioxidant and anti-inflammatory, to decrease cerebral edema after TBI thereby improving neurological outcome in the animals. The decreased edema was accompanied by a decreased peri-contusional expression of both AQP4 and NKCC1 although the mechanism of the drug action was not demonstrated. Interestingly the authors showed that inhibition of NKCC1 with bumetanide inhibited the excess expression of AQP4 indicating a functional interaction between the two proteins [115].

A functional interaction between NKCC1 and AQP4 was also demonstrated in a spinal cord injury model in rats [10]. The edema, that is commonly associated with such an injury, was attenuated by pretreatment with an AQP4 inhibitor (TGN-20) and an NKCC1 inhibitor (bumetanide). The beneficial effects of the two drugs on edema formation were additive when compared to individual effects. Treatment with TGN-20 reduced the mRNA and protein expression of AQP4 as expected, but also reduced NKCC1 expression. Conversely, treatment with bumetanide inhibited both NKCC1 and AQP4 overexpression [10]. Thus, at least in injury models, there seems to be a functional interaction between NKCC1 and AQP4 in the formation of injury promoting edema formation.

Loop diuretics such as furosemide and bumetanide, while effective inhibitors of NKCC1, are more often associated with inhibition of NKCC2 found in the kidney. While in vitro and in vivo brain infusion studies indicate that inhibition of NKCC1 may be effective for the treatment of a variety of conditions including ischemia, traumatic brain injury, and hydrocephalus, the classical NKCC inhibitors are not used clinically to treat these conditions. In part this is because they do not cross the blood brain barrier, and, therefore, would have to be administered intrathecally, but also due to the relatively ubiquitous distribution of NKCC1 expression in the brain with different functions in each cell type [108].

\section{VRAC}

VRAC, is a multifunctional channel involved in astrocyte RVD. In rodent primary astrocytes, activation of the channel in response to a hypotonic challenge or swelling results in the efflux of $\mathrm{Cl}^{-}$as well as organic osmolytes such a taurine, glutamate and aspartate [116119]. The accompanying release of excitatory amino acids will have multiple other effects on neighboring cells including neurons [118].

The VRAC transport complex in astrocytes was recently shown to contain a leucinerich repeat-containing 8 (LRRC8) subunit which is essential for swelling-activated $\mathrm{Cl}^{-}$flux and release of taurine, asparate and glutamine [119-122]. RVD is generally associated with a net loss of intracellular $\mathrm{K}^{+}$together with the efflux of anions [31]. Activation of VRAC containing LRRC8 by cell swelling allows for the efflux of $\mathrm{Cl}^{-}$which provides a driving force for $\mathrm{K}^{+}$secretion that, in turn, causes compensatory water movement out of the cell [119, 123-125]. Patch clamp experiments in rat cultured astrocytes indicated that knockdown of $\mathrm{AQP} 4$ decreased the VRAC-mediated $\mathrm{Cl}^{-}$current implying a functional interaction between the transporters [126]. Conversely, recent experiments have shown that knockdown of VRAC had no effect on water permeability in rat primary astrocytes [119]. 


\section{Cellular Physiology Cell Physiol Biochem 2022;56(S2):12-30 \\ \begin{tabular}{ll|l} 
and Biochemistry & $\begin{array}{l}\text { DOl: 10.33594/000000495 } \\
\text { Published online: } 9 \text { February } 2022\end{array}$ & $\begin{array}{l}\text { O } 2022 \text { The Author(s). Published by } \\
\text { Cell Physiol Biochem Press GmbH\&Co. KG }\end{array}$ \\
\cline { 2 - 3 } &
\end{tabular} \\ Reed et al.: Channels and Transporters in Astrocyte Volume Regulation}

Currently VRAC inhibitors are relatively non-specific complicating both research protocols as well as the potential development of pharmaceutical targets. The elucidation of some of the critical subunits like LRRC8 may enhance development of more specific blockers of this channel.

\section{Kir4.1}

The inwardly rectifying Kir4.1 potassium channel in astrocyte endfeet is responsible for the uptake of $\mathrm{K}^{+}$from the extracellular fluid during periods of high neuronal activity [120]. Failure of this clearance mechanism slows the re-equilibration of $\mathrm{K}^{+}$and can cause changes in neuronal function including seizures [54]. Under normal circumstances, the potential for astrocyte swelling during $\mathrm{K}^{+}$influx is moderated by functional interaction between astrocytes via gap junctions in the endfeet. Originally proposed by Orkland, "spatial buffering" is envisioned as the uptake of $\mathrm{K}^{+}$followed by flow through the astrocyte syncytium formed by the gap junctions to distant sites for efflux [127]. Thus, under normal conditions there is, at most, only localized swelling of the astrocytes. The Kir4.1 channel likely absorbs the excess $\mathrm{K}^{+}$as it being produced while $\mathrm{Na}^{+} / \mathrm{K}^{+}$ATPase pump is responsible for the poststimulus recovery necessary for a normalization of the extracellular space [25]. Kir2.1 is also expressed in astrocytes and may play an important role in $\mathrm{K}^{+}$spatial buffering as well, although not directly implicated in osmotic regulation [128, 129]. Both Kir channels and $\mathrm{Na}^{+} / \mathrm{K}^{+}$ATPase are necessary to maintain normal extracellular composition but the proteins are important within different time frames.

Kir4.1 has been shown to interact with AQP4 [39, 130]. Whether the interaction between the two transporters is important for cell swelling is debated [25], though studies have shown that AQP4 null astrocytes are connected to a greater degree by gap junctions and are more efficient at $\mathrm{K}^{+}$spatial buffering [120]. The functional interactions and control of the transport under normal physiological and pathological conditions awaits future studies.

\section{Conclusions and Future Perspectives}

An understanding of the control of key transporters as well as the interactions between them is crucial for the treatment of brain disorders with aberrations in fluid/electrolyte balance. Such disorders represent a substantial medical burden in the population and include stroke, infection, traumatic brain injury and hydrocephalus. Astrocytes are key for the maintenance of the composition of the extracellular milieu in the brain. In this homeostatic process, various astrocytic channels and transporters are required to maintain normal cell volume, primarily AQP4, TRPV4, TRPM4, $\mathrm{Na}^{+} / \mathrm{K}^{+}$ATPase, NKCC1, VRAC, and Kir4.1. Interactions between channels and transporters result in heteromultimeric structures with specific functions. These include AQP4/TRPV4, AQP4/TRMP4/SUR1, AQP4/ $\mathrm{Na}^{+} / \mathrm{K}^{+}$ ATPase/mGluR5, and AQP4/Kir4.1. The AQP4/TRPV4 complex works to reverse swelling in astrocytes with RVD [36]. Conversely, the AQP4/TRPM4 complex, in response to injury, appears to allow the influx of water and causes cell swelling [80]. $\mathrm{Na}^{+} / \mathrm{K}^{+}$ATPase couples with AQP4 and mGluR5 to cause swelling in response to injury as well [81]. NKCC1, although known to have a functional interaction with AQP4, mediates RVI by influx of water $[10,115]$. In some studies, VRAC is associated with RVD but when the protein is knocked down, cell volume is not affected [119]. Kir4.1's role in astrocyte volume regulation is still debated $[25,128,129]$. These mechanisms are all proposed to be important in astrocyte cell volume regulation.

Volume regulation in astrocytes is complex, and in many aspects, uniquely different than volume regulation in other cells. Although most of the channels and transporters expressed in astrocytes are found in other cell types, these channels and transporters are polarized to the cell body and astrocyte endfeet. This is unlike epithelial cells that have apical 
or basolateral polarization. The specific localization of these channels affects their function in astrocytes. Endfoot polarization is important in communicating or regulating other cell types, such as neurons and endothelial cells in the CNS. For example, AQP4 localization to astrocyte endfeet controls volume regulation at the paravascular space, while AQP4 cell body localization does not directly control volume changes [14-19, 39-41, 81]. Astrocytes also form unique heteromultimeric complexes to regulate their volume in response to injury and hypoosmotic conditions (Fig. 2).

Current studies explore various aspects of astrocyte cell volume, some of which may present conflicting findings. One confounding variable is the difficulty in visualizing what may be small changes during normal homeostatic processes like $\mathrm{K}^{+}$buffering and those that take place under pathological conditions. The utilization of different animal models and cell lines, as well as physiologically relevant controls may account for conflicting findings in many of the studies. There are apparent differences between various rodent models and humans. For example, there is transcriptional variation in C57BL/6 mice and Sprague Dawley rats, and cell-specific differences between rodents and humans [131, 132]. This stresses the importance of repeating studies in multiple models to find common mechanisms and assure translatability to human studies. Primary cultures are often used for the study of cell-specific volume regulation. Depending on the species used for primary culture isolation, there may be differences. Additionally, there are various types of astrocytes that may also regulate volume in specific ways [11-19], although most of these studies utilize primary cultures isolated from the cortex of animals. For example, Benfenati et al. propose that the TRPV4/ AQP4 complex is mainly in superficial paravascular astrocytes [19], while Illarionova et al. propose the importance of the AQP4/ $\mathrm{Na}^{+} / \mathrm{K}^{+} \mathrm{ATPase} / \mathrm{mGluR5}$ at neuronal synapses [81].

Recently, there has been a push for better physiological models in biology research. This includes making cell culture conditions a better physiological representation of in vivo conditions. Risher et al., found that depending on the specific stimulus, hypoosmotic challenge, extracellular $\mathrm{K}^{+}$elevations or oxygen/glucose deprivation, determined the specific volume response of astrocytes [67]. This study used experimental parameters that closely mimicked in vivo conditions. Utilizing endogenous channel and transporter modulators may also help the field better understand cell volume mechanisms in vivo. Overall, comparing experimental parameters of studies with conflicting findings may help guide future research in a more positive direction.

There are a multitude of directions to explore to further understand fluid regulation in astrocytes. A better understanding of how the different AQP4 isoforms function in astrocytes alone, but also in the various heteromultimeric complexes presents an interesting aspect of emerging research. This is important considering research showing that localization and water permeability vary with the different AQP4 isoforms [42-51]. Isoform specific influences may also be found for other channels and transporters, such as TRPV4 that has glycosylated isoforms that affect membrane trafficking $[98,133]$. Post-translation modification of these channels and transporters is also an important consideration for future studies. Additionally, identifying upstream modulators of heteromultimeric complex formation is another emerging area of research. For example, Kitchen et al. have have reported that protein kinase A and calmodulin have roles in AQP4 membrane localization via upstream influences of TRPV4 and direct modulation of AQP4 [72]. Another interesting aspect, not explored in this review, would be age-specific differences. The effects of development on brain fluid regulation are yet to be explored. Pediatric forms of brain fluid dysregulation are common and the developing brain is affected in different ways [134]. Also, some channels and transporters are altered during development, for example NKCC1 in the choroid plexus [135]. However, as summarized here, progress is being made, not only toward a mechanistic understanding of these complex control mechanisms but also in the field of drug development. 


\section{Cellular Physiology Cell Physiol Biochem 2022;56(S2):12-30

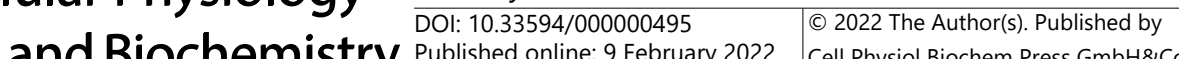 \\ \begin{tabular}{l|l} 
Published online: 9 February 2022 & Cell Physiol Biochem Press GmbH\&Co. KG \\
\hline
\end{tabular} \\ Reed et al.: Channels and Transporters in Astrocyte Volume Regulation}

\section{Acknowledgements}

The authors would like to thank our colleagues, Casandra Carrillo, Alexandra Hochstetler, and Louise Hulme for discussions and comments on the manuscript.

\section{Author Contributions}

Both authors contributed to the writing and editing of the manuscript.

\section{Funding}

Research in the authors' laboratory was funded by a Hydrocephalus Association/ Team Hydro Innovator Award; The Office of the Assistant Secretary of Defense for Health Affairs, through the Peer Reviewed Medical Research Program, Investigator Initiated Research Award No. W81XWH-17-1-0537; and a Mayfield Education and Research Foundation Award.

Statement of Ethics

The authors have no ethical conflicts to disclose.

\section{Disclosure Statement}

The authors have no conflicts of interest to declare.

\section{References}

1 Millen JW, Woollam DHM: The Anatomy of the Cerebrospinal Fluid. London, Oxford University Press, 1962.

2 Davson H, Segal MB: Physiology of the CSF and Blood-brain Barriers. Boca Raton/London, CRC Press, 1996.

3 Bito LZ, Davson H: Local variations in cerebrospinal fluid composition and its relationship to the composition of the extracellular fluid of the cortex. Exp Neurol 1966;14:264-280.

4 Merritt HH, Fremont-Smith F: The Cerebrospinal Fluid. Philadelphia/London, WB Saunders, 1937.

5 Hladky SB, Barrand MA: Mechanisms of fluid movement into, through and out of the brain: evaluation of the evidence. Fluids Barriers CNS 2014;11:26.

6 Dostovic Z, Dostovic E, Smajlovic D, Ibrahimagic OC, Avdic L: Brain Edema After Ischaemic Stroke. Med Arch 2016;70:339-341.

7 Unterberg AW, Stover J, Kress B, Kiening KL: Edema and brain trauma. Neurosci 2004;129:1021-1029.

8 Neri M, Frati A, Turillazzi E, Cantatore S, Cipolloni L, Di Paolo M, Frati P, La Russa R, Maiese A, Scopetti M, Santurro A, Sessa F, Zamparese R, Fineschi V: Immunohistochemical Evaluation of Aquaporin-4 and its Correlation with CD68, IBA-1, HIF-1 $\alpha$, GFAP, and CD15 Expressions in Fatal Traumatic Brain Injury. Int J Mol Sci 2018;19:3544.

9 Zhao H, Zhang K, Tang R, Meng H, Zou Y, Wu P, Hu R, Liu X, Feng H, Chen Y: TRPV4 blockade preserves the blood-brain barrier by inhibiting stress fiber formation in a rat model of intracerebral hemorrhage. Front Mol Neurosci 2018;11:97.

10 Yan X, Liu J, Wang X, Li W, Chen J, Sun H: Pretreatment with AQP4 and NKCC1 Inhibitors Concurrently Attenuated Spinal Cord Edema and Tissue Damage after Spinal Cord Injury in Rats. Front Physiol 2018;9:6.

11 Simard M, Nedergaard M: The neurobiology of glia in the context of water and ion homeostasis. Neurosci 2004;129:877-896.

12 Alvarez JI, Dodelet-Devillers A, Kebir H, Ifergan I, Fabre PJ, Terouz S, Sabbagh M, Wosik K, Bourbonniere L, Bernard M, van Horssen J, de Vries HE, Charron F, Prat A: The Hedgehog pathway promotes blood-brain barrier integrity and CNS immune quiescence. Science 2011;334:1727-1731.

13 Obermeier B, Daneman R, Ransohoff RM: Development, maintenance and disruption of the blood-brain barrier. Nat Med 2013;19:1584-1596.

14 Allen NJ, Barres BA: Neuroscience: Glia - more than just brain glue. Nature 2009;457:675-677.

15 Allen NJ, Bennett ML, Foo LC, Wang GX, Chakraborty C, Smith SJ, Barres BA: Astrocyte glypicans 4 and 6 promote formation of excitatory synapses via GluA1 AMPA receptors. Nature 2012;486:410-414. 


\section{Cellular Physiology Cell Physiol Biochem 2022;56(S2):12-30

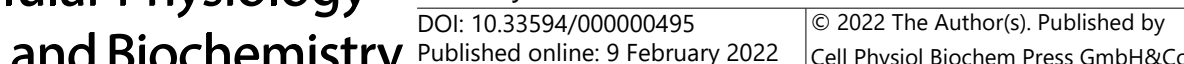 and Biochemistry Published online: 9 February 2022 Cell Physiol Biochem Press GmbH\&Co. KG \\ Reed et al.: Channels and Transporters in Astrocyte Volume Regulation}

16 Chung WS, Clarke LE, Wang GX, Stafford BK, Sher A, Chakraborty C, Joung J, Foo LC, Thompson A, Chen C, Smith SJ, Barres BA: Astrocytes mediate synapse elimination through MEGF10 and MERTK pathways. Nature 2013;504:394-400.

17 Khakh BS, Sofroniew MV: Diversity of astrocyte functions and phenotypes in neural circuits. Nat Neurosci 2015;18:942-952.

18 Molofsky AV, Kelley KW, Tsai H, Redmond SA, Chang SM, Madireddy L, Chan JR, Baranzini SE, Ullian EM, Rowitch DH: Astrocyte-encoded positional cues maintain sensorimotor circuit integrity. Nature 2014;509:189-194.

19 Tsai HH, Li H, Fuentealba LC, Molofsky AV, Taveira-Marques R, Zhuang H, Tenney A, Murnen AT, Fancy SPJ, Merkle F, Kessaris N, Alvarez-Buylla A, Richardson WD, Rowitch DH: Regional astrocyte allocation regulates CNS synaptogenesis and repair. Science 2012;337:358-362.

20 Iliff JJ, Wang M, Liao Y, Plogg BA, Peng W, Gundersen GA, Benveniste H, Vates GE, Deane R, Goldman SA, Nagelhus EA, Nedergaard M: A paravascular pathway facilitates CSF flow through the brain parenchyma and the clearance of interstitial solutes, including amyloid $\beta$. Sci Transl Med 2012;4:147ra111.

21 Jessen NA, Munk AS, Lundgaard I, Nedergaard M: The Glymphatic System: A Beginner's Guide. Neurochem Res 2015;40:2583-2599.

22 Iliff JJ, Nedergaard M: Is there a cerebral lymphatic system?. Stroke 2013;44:S93-S95.

23 Johnston M, Zakharov A, Papaiconomou C, Salmasi G, Armstrong D: Evidence of connections between cerebrospinal fluid and nasal lymphatic vessels in humans, non-human primates and other mammalian species. Cerebrospinal Fluid Res 2004;1:2.

24 Murtha LA, Yang Q, Parsons MW, Levi CR, Beard DJ, Spratt NJ, McLeod DD: Cerebrospinal fluid is drained primarily via the spinal canal and olfactory route in young and aged spontaneously hypertensive rats. Fluids Barriers CNS 2014;11:12.

25 Larsen BR, Assentoft M, Cotrina ML, Hua SZ, Nedergaard M, Kaila K, Voipio J, MacAulay N: Contributions of the $\mathrm{Na}^{+} / \mathrm{K}^{+}$-ATPase, NKCC1, and Kir4.1 to hippocampal $\mathrm{K}^{+}$clearance and volume responses. Glia 2014;62:608-622.

26 Häussinger D, Kircheis G, Fischer R, Schliess F, vom Dahl S: Hepatic encephalopathy in chronic liver disease: a clinical manifestation of astrocyte swelling and low-grade cerebral edema?. J Hepatol 2000;32:10351038.

27 Hirrlinger PG, Wurm A, Hirrlinger J, Bringmann A, Reichenbach A: Osmotic swelling characteristics of glial cells in the murine hippocampus, cerebellum, and retina in situ. J Neurochem 2008;105:1405-1417.

28 Kempski O: Cerebral edema. Semin Nephrol 2001;21:303-307.

29 Stokum JA, Kurland DB, Gerzanich V, Simard JM: Mechanisms of Astrocyte-Mediated Cerebral Edema. Neurochem Res 2015;40:317-328.

30 Lang F, Busch GL, Ritter M, Völkl H, Waldegger S, Gulbins E, Häussinger Dz: Functional significance of cell volume regulatory mechanisms. Physiol Rev 1998;78:247-306.

31 Verbalis JG, SR Gullans: Hyponatremia causes large sustained reductions in brain content of multiple organic osmolytes in rats. Brain Res 1991;567:274-282.

32 Palfrey HC: Protein phosphorylation control in the activity of volume-sensitive transport systems; in Kevin Strange (eds): Cellular and Molecular Physiology of Cell Volume Regulation. Boca Raton/London, CRC Press, 1994, pp 201-214.

33 Parker JC: Coordinated regulation of volume-activated transport pathways; in Kevin Strange (eds): Cellular and Molecular Physiology of Cell Volume Regulation. Boca Raton/London, CRC Press, 1994, pp 311-324.

34 Solenov E, Watanabe H, Manley GT, Verkman AS: Sevenfold-reduced osmotic water permeability in primary astrocyte cultures from AQP-4-deficient mice, measured by a fluorescence quenching method. Am J Physiol Cell Physiol 2004;286:C426-C432.

35 Benfenati V, Caprini M, Dovizio M, Mylonakou MN, Ferroni S, Petter Ottersen O, Amiry-Moghaddam M: An aquaporin-4/transient receptor potential vanilloid 4 (AQP4/TRPV4) complex is essential for cell-volume control in astrocytes. Proc Natl Acad Sci U S A 2011;108:2563-2568.

36 Nielsen S, Nagelhus EA, Amiry-Moghaddam M, Bourque C, Agre P, Otterson OP: Specialized membrane domains for water transport in glial cells: High-resolution immunogold cytochemistry of aquaporin-4 in rat brain. J Neurosci 1997;17:171-180. 
37 Rash JE, Yasumura T, Hudson CS, Agre P, Nielsen S: Direct immunogold labeling of aquaporin-4 in square arrays of astrocyte and ependymocyte plasma membranes in rat brain and spinal cord. Proc Natl Acad Sci U S A 1998;95:11981-11986.

38 Amiry-Moghaddam M, Petter Ottersen 0: The molecular basis of water transport in the brain. Nat Rev Neurosci 2003;4:991-1001.

39 Verbalis JG: Control of brain volume during hypoosmolality and hyperosmolality. Adv Exp Med Biol 2006; DOI: $10.1007 / 0-387-30172-0 \_8$.

40 Amiry-Moghaddam M, Frydenlund DS, Petter Ottersen 0: Anchoring of aquaporin-4 in brain: Molecular mechanisms and implications for the physiology and pathophysiology of water transport. Neurosci 2004;129:999-1010.

41 Moe SE, Sorbo JG, Sogaard R, Zeuthen T, Petter Ottersen O, Holen T: New isoforms of rat Aquaporin-4. Genom 2008;91:367-377.

42 Jung JS, Bhat RV, Preston GM, Guggino WB, Baraban JM, Agre P: Molecular characterization of an aquaporin cDNA from brain: Candidate osmoreceptor and regulator of water balance. Proc Natl Acad Sci U S A 1994;91:13052-13056.

43 Hasegawa H, Ma T, Skach W, Matthay MA, Verkman AS: Molecular cloning of a mercurial-insensitive water channel expressed in selected water-transporting tissues. J Biol Chem 1994;269:5497-5500.

44 Neely JD, Christensen BM, Nielsen S, Agre P: Heterotetrameric composition of aquaporin-4 water channels. Biochem 1999;38:11156-11163.

45 Lu M, Lee MD, Smith BL, Jung JS, Agre P, Verdijk MA, Merkx G, Rijss JP, Deen PM: The human AQP4 gene: Definition of the locus encoding two water channel polypeptides in brain. Proc Natl Acad Sci U S A 1996;93:10908-10912.

46 Yang B, Ma T, Verkman AS: cDNA cloning, gene organization, and chromosomal localization of a human mercurial insensitive water channel: Evidence for distinct transcriptional units. J Biol Chem 1995;270:22907-22913.

47 Mola M, Sparaneo A, Gargano C, Spray DC, Svelto M, Frigeri A, Scemes E, Nicchia G: The speed of swelling kinetics modulates cell volume regulation and calcium signaling in astrocytes: A different point of view on the role of aquaporins. Glia 2016;64:139-154.

48 Potokar M, Stenovec M, Jorgacevski J, Holen T, Kreft M, Otterson OP, Zorec R: Regulation of AQP4 surface expression via vesicle mobility in astrocytes. Glia 2013;61:917-928.

49 Lisjak M, Potokar M, Rituper B, Jorgačevski J, Zorec R: AQP4e-Based Orthogonal Arrays Regulate Rapid Cell Volume Changes in Astrocytes. J Neurosci 2017;37:10748-10756.

50 Lisjak M, Potokar M, Zorec R, Jorgačevski J: Indirect Role of AQP4b and AQP4d Isoforms in Dynamics of Astrocyte Volume and Orthogonal Arrays of Particles. Cells 2020;9:735.

51 Ma T, Yang B, Gillespie A, Carlson EJ, Epstein CJ, Verkman AS: Generation and phenotype of a transgenic knockout mouse lacking the mercurial-insensitive water channel aquaporin-4. J Clin Invest 1997;100:957962.

52 Saadoun S, Papadopoulos MC, Watanabe H, Yan D, Manley GT, Verkman AS: Involvement of aquaporin-4 in astroglial cell migration and glial scar formation. J Cell Sci 2005;118:5691-5698.

53 Binder DK, Yao X, Verkman AS, Manley GT: Increased seizure duration in mice lacking aquaporin-4 water channels. Acta Neurochir Suppl 2006;96:389-392.

54 Skucas VA, Mathews IB, Yang J, Cheng Q, Treister A, Duffy AM, Scharfman HE: Impairment of select forms of spatial memory and neurtrophin-dependent synaptic plasticity by deletion of glial aquaporin-4. J Neurosci 2011;31:6392-6397.

55 Scharfman HE, Binder DK: Aquaporin-4 water channels and synaptic plasticity in the hippocampus. Neurochem Int 2013;63:702-711.

56 Fan Y, Zhang J, Sun XL, Gao L, Zeng XN, Ding JH, Cao C, Niu L, Hu G: Sex- and region-specific alterations of basal amino acid and monoamine metabolism in the brain of aquaporin-4 knockout mice. J Neurosci Res 2005;82:458-464.

57 Zeng XN, Sun XL, Gao L, Fan Y, Ding JH, Hu G: Aquaporin-4 deficiency down-regulates glutamate uptake and GLT-1 expression in astrocytes. Mol Cell Neurosci 2007;34:34-39.

58 Li YK, Wang F, Wang W, Luo Y, Wu PF, Xiao JL, Hu ZL, Jin Y, Hu G, Chen JG: Aquaporin-4 deficiency impairs synaptic plasticity and associative fear memory in the lateral amygdala: involvement of downregulation of glutamate transporter-1 expression. Neuropsychopharmacol 2012;37:1867-1878. 


\section{Cellular Physiology Cell Physiol Biochem 2022;56(S2):12-30

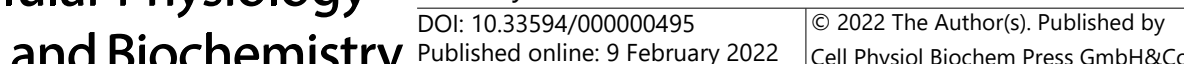 and Biochemistry Published online: 9 February 2022 Cell Physiol Biochem Press GmbH\&Co. KG \\ Reed et al.: Channels and Transporters in Astrocyte Volume Regulation}

59 Hiroaki Y, Tani K, Kamegawa A, Gyobu N, Nishikawa K, Suzuki H, Walz T, Sasaki S, Mitsuoka K, Kimura K, Mizoguchi A, Fujiyoshi Y: Implications of the aquaporin-4 structure on array formation and cell adhesion. J Mol Biol 2006;355:628-639.

60 Binder DK, Papadopoulos MC, Haggie PM, Verkman AS: In vivo measurement of brain extracellular space diffusion by cortical surface photobleaching. J Neurosci 2004;24:8049-8056.

61 Haj-Yasein NN, Jensen V, Ostby I, Omholt SW, Voipio J, Kaila K, Petter Ottersen O, Hvalby O, Nagelhus EA: Aquaporin-4 regulates extracellular space volume dynamics during high-frequency synaptic stimulation: A gene deletion study in mouse hippocampus. Glia 2012;60:867-874.

62 Mack AF, Wolburg H: A Novel Look at Astrocytes: Aquaporins, Ionic Homeostasis, and the Role of the Microenvironment for Regeneration in the CNS. Neuroscientist 2013;19:195-207.

$63 \mathrm{Xu}$ Z, Xiao N, Chen Y, Huang H, Marshall C, Gao J, Xiao M: Deletion of aquaporin-4 in APP/PS1 mice exacerbates brain $A \beta$ accumulation and memory deficits. Mol Neurodegener 2015;10:58.

64 Skjolding AD, Rowland IJ, Søgaard LV, Praetorius J, Penkowa M, Juhler M: Hydrocephalus induces dynamic spatiotemporal regulation of aquaporin-4 expression in the rat brain. Cerebrospinal Fluid Res 2010;7:20.

65 Skjolding AD, Holst AV, Broholm H, Laursen H, Juhler M: Differences in distribution and regulation of astrocytic aquaporin-4 in human and rat hydrocephalic brain. Neuropath Appl Neurobiol 2013;39:179-191.

66 Ryskamp DA, Jo AO, Phuong TT, Verkman AS, Yarishkin O, MacAulay N, Križaj D: TRPV4 and AQP4 Channels Synergistically Regulate Cell Volume and Calcium Homeostasis in Retinal Müller Glia. J Neurosci 2015;35:13525-13537.

67 Risher WC, Andrew RD, Kirov SA: Real-time passive volume responses of astrocytes to acute osmotic and ischemic stress in cortical slices and in vivo revealed by two-photon microscopy. Glia 2009;57:207-221.

68 Manley GT, Fujimura M, Ma T, Noshita N, Filiz F, Bollen AW, Chan P, Verkman AS: Aquaporin-4 deletion in mice reduces brain edema after acute water intoxication and ischemic stroke. Nat Med 2000;6:159-163.

69 Thrane AS, Rappold PM, Fujita T, Torres A, Bekar LK, Takano T, Peng W, Wang F, Thrane VR, Enger R, Haj-Yasein NN, Skare O, Holen T, Klungland A, Otterson OP, Nedergaard M, Nagelhus EA: Critical role of aquaporin-4 (AQP4) in astrocytic Ca2+ signaling events elicited by cerebral edema. Proc Natl Acad Sci U S A 2011;108:846-851.

70 Tang G, Yang GY: Aquaporin-4: A Potential Therapeutic Target for Cerebral Edema. Int J Mol Sci 2016;17:1413.

71 Papadopoulos MC, Manley GT, Krishna S, Verkman AS: Aquaporin-4 facilitates reabsorption of excess fluid in vasogenic brain edema. FASEB J 2004;18:1291-1293.

72 Kitchen P, Day RE, Taylor LH, Salman MM, Bill RM, Conner MT, Conner AC: Identification and molecular mechanisms of the rapid tonicity-induced relocalization of the aquaporin 4 channel. J Biol Chem 2015;290:16873-16881.

73 Salman MM, Kitchen P, Woodroofe MN, Brown JE, Bill RM, Conner AC, Conner MT: Hypothermia increases aquaporin 4 (AQP4) plasma membrane abundance in human primary cortical astrocytes via a calcium/ transient receptor potential vanilloid 4 (TRPV4)- and calmodulin-mediated mechanism. Eur J Neurosci 2017;46:2542-2547.

74 Kitchen P, Salman MM, Halsey AM, Clarke-Bland C, MacDonald JA, Ishida H, Vogel HJ, Almutiri S, Logan A, Kreida S, Al-Jubair T, Winkel Missel J, Gourdon P, Törnroth-Horsefield S, Conner MT, Ahmed Z, Conner AC, Bill RM: Targeting Aquaporin-4 Subcellular Localization to Treat Central Nervous System Edema. Cell 2020;181:784-799.e19.

75 Huber VJ, Tsujita M, Yamazaki M, Sakimura K, Nakada T: Identification of arylsulfonamides as Aquaporin 4 inhibitors. Bioorg Med Chem Lett 2007;17:1270-1273.

76 Huber VJ, Tsujita M, Kwee IL, Nakada T: Inhibition of aquaporin 4 by antiepileptic drugs. Bioorg Med Chem 2009;17:418-424.

77 Huber VJ, Tsujita M, Nakada T: Identification of aquaporin 4 inhibitors using in vitro and in silico methods. Bioorg Med Chem 2009;17:411-417.

78 Igarashi H, Huber VJ, Tsujita M, Nakada T: Pretreatment with a novel aquaporin 4 inhibitor, TGN-020, significantly reduces ischemic cerebral edema. Neurol Sci 2011;32:113-116.

79 Li J, Jia Z, Xu W, Guo W, Zhang M, Bi J, Cao Y, Fan Z, Li G: TGN-020 alleviates edema and inhibits astrocyte activation and glial scar formation after spinal cord compression injury in rats. Life Sci 2019;222:148-157. 


\section{Cellular Physiology Cell Physiol Biochem 2022;56(S2):12-30 \begin{tabular}{ll|l} 
Dol: 10.33594/000000495 202022 The Author(s). Published by \\
\hline and Biochemistry
\end{tabular} and Biochemistry Published online: 9 February 2022 Cell Physiol Biochem Press GmbH\&Co. KG \\ Reed et al.: Channels and Transporters in Astrocyte Volume Regulation}

80 Stokum JA, Kwon MS, Woo SK, Tsymbalyuk O, Vennekens R, Gerzanich V, Simard JM: SUR1-TRPM4 and AQP4 form a heteromultimeric complex that amplifies ion/water osmotic coupling and drives astrocyte swelling. Glia 2018;66:108-125.

81 Illarionova NB, Gunnarson E, Li Y, Brismar H, Bondar A, Zelenin S, Aperia A: Functional and molecular interactions between aquaporins and Na,K-ATPase. Neurosci 2010;168:915-925.

82 Mutai H, Heller S: Vertebrate and invertebrate TRPV-like mechanoreceptors. Cell Calcium 2003;33:471-478.

83 Liedtke W: Transient receptor potential vanilloid channels functioning in transduction of osmotic stimuli. J Endocrinol 2006;191:515-523.

84 Becker D, Blase C, Bereiter-Hahn J, Jendrach M: TRPV4 exhibits a functional role in cell-volume regulation. J Cell Sci 2005;118:2435-2440.

85 Liedtke W, Friedman JM: Abnormal osmotic regulation in trpv4-/- mice. Proc Natl Acad Sci U S A 2003;100:13698-13703.

86 Benfenati V, Amiry-Moghaddam M, Caprini M, Mylonakou MN, Rapisarda C, Petter Ottersen O, Ferroni S: Expression and functional characterization of transient receptor potential vanilloid-related channel 4 (TRPV4) in rat cortical astrocytes. Neuroscience 2007;148:876-892.

87 Becker D, Bereiter-Hahn J, Jendrach M: Functional interaction of the cation channel transient receptor potential vanilloid 4 (TRPV4) and actin in volume regulation. Eur J Cell Biol 2009;88:141-152.

88 Vincent F, Duncton MA: TRPV4 agonists and antagonists. Curr Top Med Chem 2011;11:2216-2226.

89 Wei ZL, Nguyen MT, O’Mahony DJ, Acevedo A, Zipfel S, Zhang Q, Liu L, Dourado M, Chi C, Yip V, DeFalco J, Gustafson A, Emerling DE, Kelly MG, Kincaid J, Vincent F, Duncton MA: Identification of orally-bioavailable antagonists of the TRPV4 ion-channel. Bioorg Med Chem Lett 2015;25:4011-4015.

90 Goyal N, Skrdla P, Schroyer R, Kumar S, Fernando D, Oughton A, Norton N, Sprecher DL, Cheriyan J: Clinical Pharmacokinetics, Safety, and Tolerability of a Novel, First-in-Class TRPV4 Ion Channel Inhibitor, GSK2798745, in Healthy and Heart Failure Subjects. Am J Cardiovasc Drugs 2019;19:335-342.

91 Tanaka K, Matsumoto S, Yamada T, Yamasaki R, Suzuki M, Kido MA, Kira JI: Reduced Post-ischemic Brain Injury in Transient Receptor Potential Vanilloid 4 Knockout Mice. Front Neurosci 2020;14:453.

92 Shen J, Tu L, Chen T, Tan T, Wang Y, Wang S: TRPV4 channels modulate $\mathrm{Ca}^{2+}$-induced $\mathrm{Ca}^{2+}$ release in mouse neurons and trigger endoplasmic reticulum stress after intracerebral hemorrhage. Brain Res Bull 2019;146:143-152.

93 Jie P, Lu Z, Hong Z, Li L, Zhou L, Li Y, Zhou R, Zhou Y, Du Y, Chen L, Chen L: Activation of Transient Receptor Potential Vanilloid 4 is Involved in Neuronal Injury in Middle Cerebral Artery Occlusion in Mice. Mol Neurobiol 2016;53:8-17.

94 Ryskamp DA, Jo AO, Frye AM, Vazquez-Chona F, MacAulay N, Thoreson WB, Križaj D: Swelling and eicosanoid metabolites differentially gate TRPV4 channels in retinal neurons and glia. J Neurosci 2014;34:15689-15700.

95 Asao Y, Tobori S, Kakae M, Nagayasu K, Shibasaki K, Shirakawa H, Kaneko S: Transient receptor potential vanilloid 4 agonist GSK1016790A improves neurological outcomes after intracerebral hemorrhage in mice. Bioche Biophys Res Commun 2020;529:590-595.

96 Chen CK, Hsu PY, Wand TM, Miao ZF, Lin RT, Juo SHH: TRPV4 activation contributes functional recovery from ischemic stroke via angiogenesis and neurogenesis. Mol Neurobiol 2018;55:4127-4135.

97 Liu M, Liu X, Wang L, Wang Y, Dong F, Wu J, Qu X, Liu Y, Liu Z, Fan H, Yao R: TRPV4 Inhibition Improved Myelination and Reduced Glia Reactivity and Inflammation in a Cuprizone-Induced Mouse Model of Demyelination. Front Cell Neurosci 2018;12:392.

98 Hochstetler AE, Smith HM, Preston DC, Reed MM, Territo PR, Shim JW, Fulkerson D, Blazer-Yost BL: TRPV4 antagonists ameliorate ventriculomegaly in a rat model of hydrocephalus. JCI Insight 2020;5:e137646.

99 Chen M, Simard JM: Cell swelling and a nonselective cation channel regulated by internal Ca2+ and ATP in native reactive astrocytes from adult rat brain. J Neurosci 2001;21:6512-6521.

100 Chen M, Dong Y, Simard JM: Functional coupling between sulfonylurea receptor type 1 and a nonselective cation channel in reactive astrocytes from adult rat brain. J Neurosci 2003;23:8568-8577.

101 Simard JM, Chen M, Tarasov KV, Bhatta S, Ivanova S, Melnitchenko L, Tsymbalyuk N, West GA, Gerzanich V: Newly expressed SUR1-regulated NC(Ca-ATP) channel mediates cerebral edema after ischemic stroke. Nat Med 2006;12:433-440. 


\section{Cellular Physiology Cell Physiol Biochem 2022;56(S2):12-30

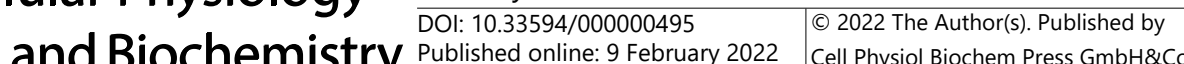 and Biochemistry Published online: 9 February 2022 Cell Physiol Biochem Press GmbH\&Co. KG \\ Reed et al.: Channels and Transporters in Astrocyte Volume Regulation}

102 Mehta RI, Tosun C, Ivanova S, Tsymbalyuk N, Famakin BM, Kwon MS, Castellani RJ, Gerzanich V, Simard JM: Sur1-Trpm4 Cation Channel Expression in Human Cerebral Infarcts. J Neuropathol Exp Neurol 2015;74:835-849.

103 Sheth KN, Simard JM, Elm J, Kronenberg G, Kunte H, Kimberly WT: Human data supporting glyburide in ischemic stroke. Acta Neurochir Suppl 2016;121:13-18.

104 Delalande C, Awale M, Rubin M, Probst D, Ozhathil LC, Abriel H, Reymond JL: Optimizing TRPM4 inhibitors in the MHFP6 chemical space. Eur J Med Chem 2019;166:167-177.

105 Chen B, Gao Y, Wei S, Low SW, Ng G, Yu D, Tu TM, Soong TW, Nilius B, Liao P: TRPM4-specific blocking antibody attenuates reperfusion injury in a rat model of stroke. Pflugers Arch 2019;471:1455-1466.

106 Walch E, Murphy TR, Cuvelier N, Aldoghmi M, Morozova C, Donohue J, Young G, Samant A, Garcia S, Alvarez C, Bilas A, Davila D, Binder DK, Fiacco TA: Astrocyte-Selective Volume Increase in Elevated Extracellular Potassium Conditions Is Mediated by the $\mathrm{Na}^{+} / \mathrm{K}^{+}$ATPase and Occurs Independently of Aquaporin 4. ASN Neuro 2020;12:1759091420967152.

107 Murakami S, Kurachi S: Mechanisms of astrocytic K+ clearance and swelling under extracellular K+ concentrations. J Physiol Sci 2016;66:127-142.

108 Chen H, Sun D: The role of Na-K-Cl co-transporter in cerebral ischemia. Neurol Res 2005;27:280-286.

109 Staub F, Stoffel M, Berger S, Eriskat J, Baethmann A: Treatment of vasogenic brain edema with the novel Clctransport inhibitor torasemide. J Neurotrauma 1994;11:679-690.

110 MacVicar B, Hochman D: Imaging of synaptically evoked intrinsic optical signals in hippocampal slices. J Neurosci 1991;11:1458-1469.

111 MacVicar BA, Feighan D, Brown A, Ransom B: Intrinsic optical signals in the rat optic nerve: role for $\mathrm{K}(+)$ uptake via NKCC1 and swelling of astrocytes. Glia 2002;37:114-123.

112 Su G, Kintner DB, Flagella M, Shull GE, Sun D: Astrocytes from Na(+)-K(+)-Cl(-) cotransporter-null mice exhibit absence of swelling and decrease in EAA release. Am J Physiol Cell Physiol 2002;282:C1147-C1160.

113 Jayakumar AR, Liu M, Moriyama M, Ramakrishnan R, Forbush B 3rd, Reddy PV, Norenberg MD: Na-K-Cl Cotransporter-1 in the mechanism of ammonia-induced astrocyte swelling. J Biol Chem 2008;283:3387433882.

114 Zeuthen T, MacAulay N: Cotransport of water by Na+-K+-2Cl- cotransporters expressed in Xenopus oocytes: NKCC1 versus NKCC2. J Physiol 2012;590:1139-1154.

115 Zhang M, Cui Z, Cui H, Cao Y, Zhong C, Wang Y: Astaxanthin alleviates cerebral edema by modulating NKCC1 and AQP4 expression after traumatic brain injury in mice. BMC Neurosci 2016;17:60.

116 Parkerson KA, Sontheimer H: Contribution of chloride channels to volume regulation of cortical astrocytes. Am J Physiol Cell Physiol 2003;284:C1460-C1467.

117 Parkerson KA, Sontheimer H: Biophysical and pharmacological characterization of hypotonically activated chloride currents in cortical astrocytes. Glia 2004;46:419-436.

118 Hyzinski-Garcia MC, Rudkouskaya A, Mongin AA: LRRC8A protein is indispensable for swelling-activated and ATP-induced release of excitatory amino acids in rat astrocytes. J Physiol 2014;592:4855-4862.

119 Formaggio F, Saracino E, Mola MG, Rao SB, Amiry-Moghaddam M, Muccini M, Zamboni R, Nicchia GP, Caprini $\mathrm{M}$, Benfenati V: LRRC8A is essential for swelling-activated chloride current and for regulatory volume decrease in astrocytes. FASEB J 2019;33:101-113.

120 Murphy TR, Binder DK, Fiacco TA: Turning down the volume: Astrocyte volume change in the generation and termination of epileptic seizures. Neurobiol Dis 2017;104:24-32.

121 Qiu Z, Dubin AE, Mathur J, Tu B, Reddy K, Miraglia LJ, Reinhardt J, Orth AP, Patapoutian A: SWELL1, a plasma membrane protein, is an essential component of volume-regulated anion channel. Cell 2014;157:447-458.

122 Voss FK, Ullrich F, Munch J, Lazarow K, Lutter D, Mah N, Andrade-Navarro MA, von Kries JP, Stauber T, Jentsch TJ: Identification of LRRC8 heteromers as an essential component of the volume-regulated anion channel VRAC. Science 2014;344:634-638.

123 Kimelberg HK, Rutledge E, Goderie S, Charniga C: Astrocytic swelling due to hypotonic or high K+ medium causes inhibition of glutamate and aspartate uptake and increases their release. J Cereb Blood Flow Metab 1995;15:409-416.

124 Vitarella D, DiRisio DJ, Kimelberg HK, and Aschner M: Potassium and taurine release are highly correlated with regulatory volume decrease in neonatal primary rat astrocyte cultures. J Neurochem 1994;63:11431149. 


\section{Cellular Physiology and Biochemistry}

Cell Physiol Biochem 2022;56(S2):12-30

\begin{tabular}{l|l}
\hline DOI: $10.33594 / 000000495$ & (c) 2022 The Author(s). Published by
\end{tabular}

Reed et al.: Channels and Transporters in Astrocyte Volume Regulation

125 Olson JE, Li GZ: Increased potassium, chloride, and taurine conductances in astrocytes during hypoosmotic swelling. Glia 1997;20:254-261.

126 Benfenati V, Nicchia GP, Svelto M, Rapisarda C, Frigeri A, Ferroni S: Functional down-regulation of volumeregulated anion channels in AQP4 knockdown cultured rat cortical astrocytes. J Neurochem 2007;100:87104.

127 Orkand R, Nicholls J, Kuffler S: Effect of nerve impulses on the membrane potential of glial cells in the central nervous system of amphibia. J Neurophysiol 1966;29:788-806.

128 Howe MW, Feig SL, Osting SM, Haberly LB: Cellular and subcellular localization of Kir2.1 subunits in neurons and glia in piriform cortex with implications for K+ spatial buffering. J Comp Neurol 2008;506:877-893.

129 Kang SJ, Cho SH, Park K, Yi J, Yoo SJ, Shin KS: Expression of Kir2.1 channels in astrocytes under pathophysiological conditions. Mol Cells 2008;25:124-130.

130 Nagelhus EA, Mathiisen TM, Petter Ottersen 0: Aquaporin-4 in the central nervous system: cellular and subcellular distribution and coexpression with KIR4.1. Neurosci 2004;129:905-913.

131 Francis C, Natarajan S, Lee MT, Khaladkar M, Buckley PT, Sul JY, Eberwine J, Kim J: Divergence of RNA localization between rat and mouse neurons reveals the potential for rapid brain evolution. BMC Genomics 2014;15:883.

132 Xu X, Stoyanova EI, Lemiesz AE, Xing J, Mash DC, Heintz N: Species and cell-type properties of classically defined human and rodent neurons and glia. eLife 2018;7:e37551.

$133 \mathrm{Xu} \mathrm{H}, \mathrm{Fu}$ Y, Tian W, Cohen DM: Glycosylation of the osmoresponsive transient receptor potential channel TRPV4 on Asn-651 influences membrane trafficking. Am J Physiol Renal Physiol 2006;290:F1103-F1109.

134 Semple BD, Blomgren K, Gimlin K, Ferriero DM, Noble-Haeusslein LJ: Brain development in rodents and humans: Identifying benchmarks of maturation and vulnerability to injury across species. Prog Neurobiol 2013;106-107:1-16.

135 Xu H, Fame RM, Sadegh C, Sutin J, Naranjo C, Syau D, Cui J, Shipley FB, Vernon A, Gao F, Zhang Y, Holtzman MJ, Heiman M, Warf BC, Lin P, Lehtinen MK: Choroid plexus NKCC1 mediates cerebrospinal fluid clearance during mouse early postnatal development. Nat Commun 2021;12:447. 